\title{
STUdY OF E-COMMERCE AdVANTAGES FOR E-SUPPly CHAINS
}

\author{
Zvonko Kremljak \\ Telekom Slovenije, d. d., ONE (Skopje), Cigaletova 15, SI - 1000 Ljubljana, Slovenia, European Union
}

\begin{abstract}
E-commerce creates more efficient supply chains that benefits both customers and manufacturers. Companies can better serve customer needs, carry less inventory, and send products to market more quickly. E-commerce impacts supply chain management in different ways.

This paper demonstrates the impact of e-commerce on business models and analyses the implications of e-commerce to companies. The exponential growth of e-business, together with the emergence of a low-cost, worldwide communication network is reshaping the way that the individuals and business carry out their transactions. The results of the study show the increased web presence of companies, mainly used for marketing activities and customer management. Because of overall importance, companies cannot ignore e-commerce advantages for e-supply chains any longer. The greatest challenge now is to keep the e-supply chain highly flexible.
\end{abstract}

Keywords: e-commerce; e-supply chain; web presence; data analysis; impact; benefit
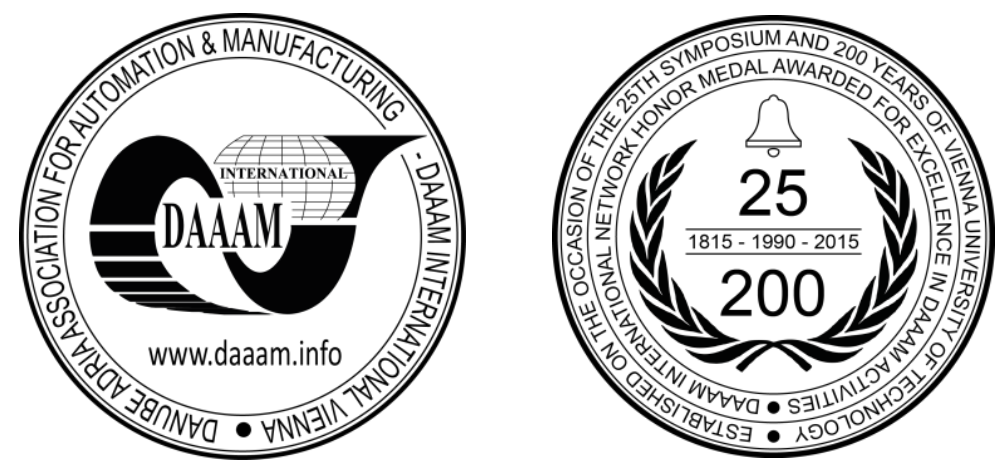

This Publication has to be referred as: Kremljak, Z[vonko] (2016). Study of E-Commerce Advantages for E-Supply Chains, Proceedings of the 26th DAAAM International Symposium, pp.0089-0096, B. Katalinic (Ed.), Published by DAAAM International, ISBN 978-3-902734-07-5, ISSN 1726-9679, Vienna, Austria

DOI:10.2507/26th.daaam.proceedings.013 


\section{Introduction}

Electronic commerce has come to encompass individual consumers as well as businesses of all sizes with the increased awareness and popularity of the internet. Internet is one of the best business communication channels with the worldwide network of computers, accessible to anyone who knows their Internet Protocol (IP) address. With perfect information about prices and products at their fingertips, consumers can quickly and easily find the best deals. The impact of e-commerce can be seen by the lower prices of the products or huge changes in logistics and delivery. The main feature of the internet is its ability to generate different pricing mechanism, and in particular, to allow price and product comparisons to be made and various kinds of auctions and exchanges to take place [1].

There is no question that e-commerce will represent a significant portion of the global economy over the next decades. To achieve its full potential, companies need to move quickly to establish market leadership, while governments must nurture electronic commerce with supportive laws and policies. The biggest technological advancement since the personal computer and the primary technological force form a base for all corporations to rethink their business model. O'Grady [2] reported that the internet is the most cost-efficient medium for business-to-consumer dealings.

E-commerce refers to all form of transactions relating to commercial activities or it means to do business online. It encompasses many diverse activities including electronic trading of goods and services, online delivery of digital content, electronic fund transfers, electronic share trading, electronic bills of lading, commercial auctions, collaborative design and engineering, online sourcing, public procurement and direct consumer marketing. It involves both products and services; traditional activities (e.g. healthcare, education) and new activities (e.g. virtual malls). It is about using the power of digital information to understand the needs and the preferences of each customer and each partner, to customize products and services for them, and then to deliver the products and services as quickly as possible. Automated services offer potential to the businesses to increase revenues at lower costs and establish or make stronger customer and partner relationships [3].

E-commerce is the exchange of information across electronic networks at any stage in the supply chain, within an organization, between companies and between companies and consumers. Because of different definitions of ecommerce, the forecasts presented by various analysts are very widely spread. Only $5 \%$ of business-to-business web sites are designed for direct sales, rather than for marketing and customer service. Even for consumer businesses, only $14 \%$ of sites offer online transactions. Almost $70 \%$ of internet users in the United States and Canada had used the internet to reach a decision on a purchase [4].

The critical success factors for e-commerce are $[4,5,6,7,8]$ : target the right customer, own the customer's total experience, streamline business processes that influence the customer, provide a holistic view of customer relationship, help customers do their job and deliver personalized service. The unique features are shown in Fig. 1 [4].

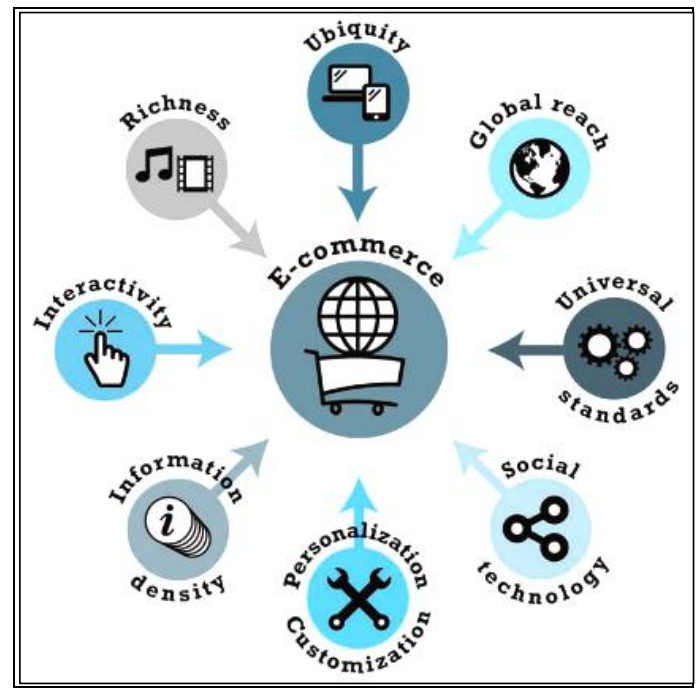

Fig. 1. Unique features that have impacted the conduct of business [4]

Kalakota and Whinston [9] reported that e-commerce is being driven by economic forces, customer interaction forces, and technology-driven digital convergence. Under relentless pressure to reduce costs and stay competitive, firms are attracted to the economic efficiencies offered by e-commerce. The economic forces that are motivating the shift of e-commerce are internal as well as external. The internal economic forces are related to the company's operations. Similarly, the external are related to the supplier, distributor and retailers. Consumer web traffic is fragmented across millions of web sites and commercial sites must compete intensely for even small share of consumer visits. This is despite the exponential growth in number of web users and time spent online. Web advertisers want consumers visit on the publisher's site to view their advertisement, and click on them to interact with advertising information. 


\subsection{E-commerce overview}

With the growing e-commerce industry in the world and major international players entering the market, the number of job offers would certainly look up. The online retail segment is expected to report strong growth in the coming years owing to growing internet consumer base due to increasing use of smartphones, laptops/PCs and availability of internet in the remotest parts of the world.

E-commerce space is a fast growing space as internet audience are likely to double every three years and this industry will require talent from various sectors like technology, product, analytics, sourcing, general management talent, merchandising and marketing. Internet consumer base is also growing rapidly, and companies within the ecommerce space can scale very fast. Meanwhile, the e-commerce sector is fast hiring the best talents available in the world at premier institutions.

On the global level, Brazil, US, Europe and China are showing tremendous growth. China is expected to add the equivalent of the entire population of Canada as e-shoppers in each of the next three years. In the urban areas, people are moving from cyber cafes to broadband connections installed in their homes, which is a positive sign. The report predicts that internet usage will continue to rise.

The internet economy is reshaping the fortunes of the businesses, countries and people, levelling the competitive environment for everyone, and driving the most significant economic shift since industrial revolution.

\section{E-supply chain}

In today's highly competitive market, products of shorter and shorter life cycle are introduced in the market and very sensitive expectations of customer have forced business enterprise to invest in, and focus their attention on supply chain [10]. A supply chain is the system of suppliers, manufacturers, transportation, distributors, and retailers that exist to transform raw materials to final products and supply those products to customers [11]. Supply chains exist in both service and manufacturing organizations, although the complexity of the supply chain may vary greatly from industry to industry and firm to firm. Generally, a supply chain can be breaks into two parts i. e. inbound and outbound, the section of the supply chain from supplier to the warehouse is known as inbound part of the supply chain and the portion of the supply chain, which comes after the warehouse, is known as outbound part of the supply chain. Once the products produced by the factories, the distribution network comes into picture that needs transportation systems and intermediate facilities to transport these products from factories to end customer [12, 13].

Traditionally, marketing, distribution, planning, manufacturing, and the purchasing organizations along the supply chain operated independently. These organizations have their own objectives and these are often conflicting. Marketing objective of high customer service and maximum sales is conflicting with manufacturing and distribution objectives [14]. Most of the manufacturing operations are designed to maximize throughput and lower costs with little consideration for the impact or inventory levels and distribution capabilities. Purchasing contracts are often negotiated with very little information beyond historical buying patterns. Optimal make-or-buy decisions are needed [15]. There is a need for a strategy through which these different functions can be integrated together and this strategy is known as supply chain management (SCM).

Online sales and distribution of the products over the internet have been putting enormous pressure on the manufacturers, who still use traditional means of sales and distribution via dealers. This brings significant changes in the supply chain. In particular, customer demand for online delivery date confirmation requires complete information transparency, a genuine pull system, and high flexibility in the supply chain from order control to the vendors [16]. This in turn means that today's prevalent and, generally speaking, inflexible planning system will be replaced by a customer specific (make-to-order) orders and orders produced for stock (make-to stock). In the quest to remove supply channel costs, streamline channel communications, and link customers to the value-added resources found along the supply chain continuum. The tightening of the economy and heavier restrictions and security measures placed on channel flows have rendered access to real-time, accurate supply chain information more critical than ever. Introduction to e-supply chain management explores the concepts, techniques, and vocabulary of the convergence of SCM and the internet so that companies can move beyond merely surviving and thrive in today's competitive marketplace [17].

\section{Methodology}

The objective of this paper is to explore the implications and advantages of e-commerce to small-, mediumsized and large companies globally on the international level. The data collected for this study involved primarily public databases and reports $[2,7,18,19,20,21]$, interviews with managers and information from company websites. Target years were 2010 and 2014. There are major implications of e-commerce for the markets both at national and international levels. It is continued with the analysis of the companies' attitudes towards doing business on the internet, the features of e-commerce, internet benefits, to compare e-commerce with more traditional forms of activities, barriers of implementing e-commerce solutions, and implications of the e-commerce on the global marketplace.

Because it is impossible to take a complete census of the whole population, statistical sampling procedures focus on collecting a small representative group of the larger population. The resulting sample provides information that can be used to estimate characteristics of the entire population. The approach used is "cluster sampling" considering 
that the included companies present no significant differences from the other companies, for example: considering a level of accuracy of $10 \%$ either way, for the population of 10.000 companies the sample size required is approx. 10 (1 $\%$ ). This research reflects the attitude of the companies toward e-commerce, based on the assumption that the results are not significantly different then in the neglected business areas.

The areas of interest were divided into six sections: e-commerce features, internet benefits, enhancing companies' credibility and security issues, overcoming problems, reasons for not doing business on the internet and web presence.

\section{Results}

The dynamic analysis of the proportion of companies with a web presence reflects the view of the data for the years 2010 and 2014. In 2010 there were $66 \%$ of the companies with a web presence. The situation has changed with an increase of $19 \%$ in the number of companies with a web presence in 2014 (Fig. 2).
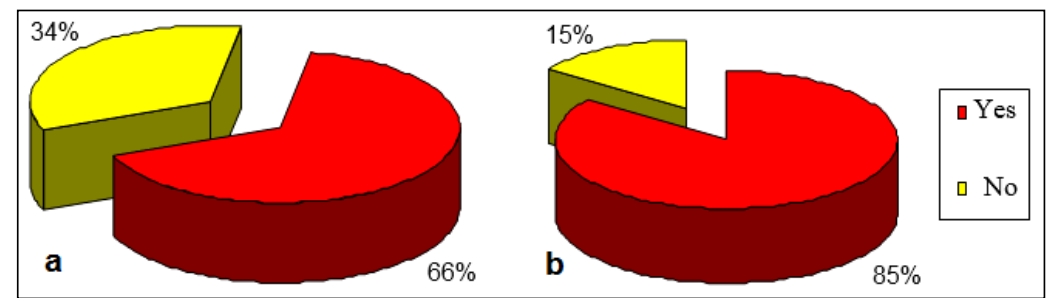

Fig. 2. Proportion of companies with a web presence in 2010 (a) and in 2014 (b)

Company web presence: The most important primary reason for the company's web presence was marketing purpose (69\% of the companies). The interesting factor is that the revenue generation is on the second position (26\%), followed by the customer service (11\%); see Fig. 3.

Regarding the companies' attitudes towards doing business on the internet $63 \%$ of them believe that the internet can gain competitive edge for the business. Results indicate that allocating a significant marketing budget dedicated to internet marketing is not a very stringent requirement, but there is a positive correlation for the success of internet business. Most of the companies (54\%) believe that internet activities are a critical component for the company success (Fig. 4). The results also indicate that there is not a significant difference between companies regarding the internet as a critical activity. Purely e-commerce businesses will yield a higher score, comparing with traditional businesses.

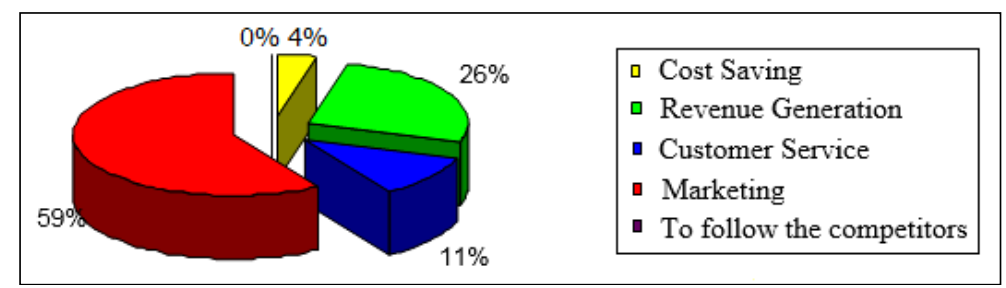

Fig. 3. Primary reasons for companies' web presence

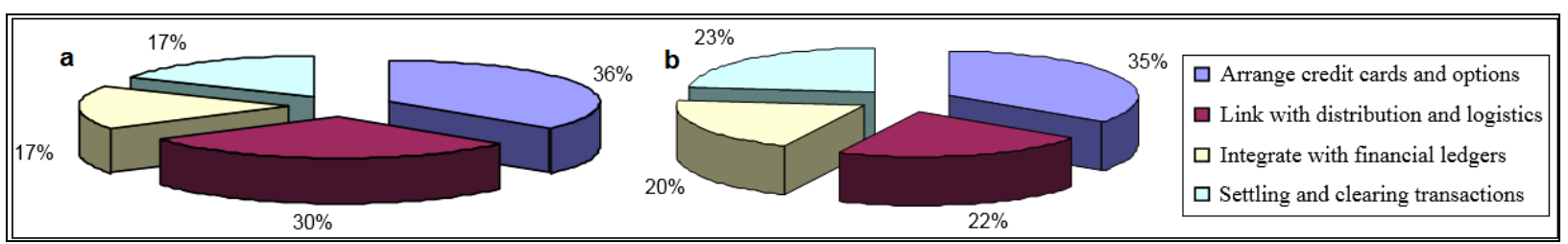

Fig. 4. E-commerce activity in 2010 (a) and in 2014 (b)

The majority of the companies are implementing credit and payment options. There is a movement in the tendency of integrating with financial ledgers ( $6 \%$ increases in the number of companies).

Features of e-commerce: Most of the companies (63\%) believe that their company business strategies are well integrated with internet strategies. A deeper research should be carried out in order to identify the differences, if any between traditional firms and purely e-commerce companies. Similarly, $56 \%$ of the companies believe that the company's internet applications are driven by customer need. Versatility of e-commerce solution is one of the main features allowing companies to permanently adapt their efforts to the increasing external pressure. Majority of the companies $(89 \%)$ consider that the internet solutions are versatile enough to cope up the future need. $81 \%$ of 
companies believe that the e-commerce strategy eliminates geographical boundaries. $70 \%$ of the companies have an ecommerce monitoring system that prioritize and drives internet activities. This is proved by the fact that e-commerce solutions are well integrated with company's business strategies.

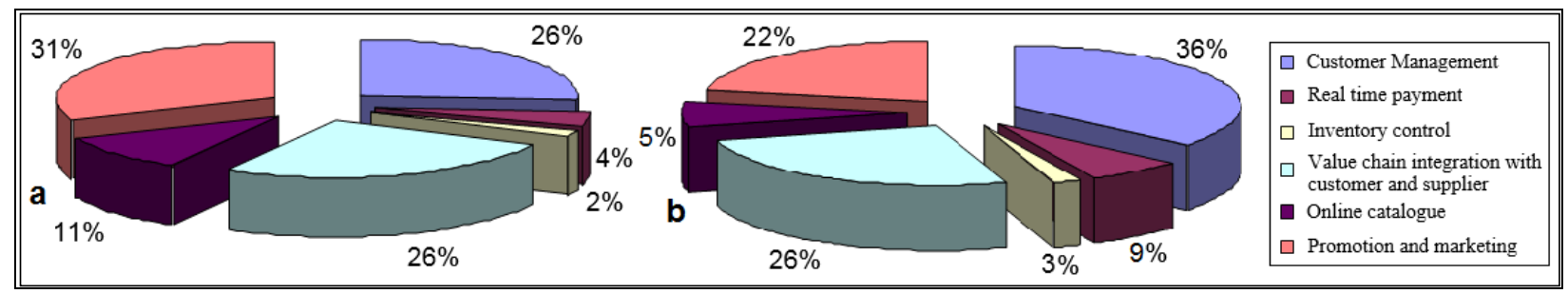

Fig. 5. Most important features of company e-commerce solution in 2010 (a) and in 2014 (b)

For the year 2014, customer management was on the top priority by most of the companies, followed by promotion and marketing (Fig. 5). Obviously, there is a shift from the first attempt of the companies to go on the web with a dynamic online catalogues, to a more interactive and customizable services to individual customers, thanks to their customizable databases.

Benefits of e-commerce: The main way for the companies to earn revenue on the e-commerce applications is for the current period "cost cutting". Because of the integration of the value chains, company's website will become "a virtual shop" for both the consumers and suppliers. The most important benefits of e-commerce solutions are:

- access to new market and customers,

- $\quad$ speed of doing business,

- flexibility / adaptability,

- low entry / exit barrier,

- simplification of tasks, etc.

Online purchasing vs. Traditional purchasing: In 2010, $56 \%$ of the companies consider the internet as a more cost effective medium comparing with the traditional methods. In 2014, this has changed, so that $85 \%$ of the companies share this view.

Company credibility and security issues: Although most of the companies have a formal security policy (56\% for 2010), due to the increasing number of security issues in five-year time the majority of the companies (93\%) implement security systems in order to build customer trust. Only two thirds of the companies believe that their company security system for the web applications is adequate. During investigation the following main reasons that hinder the implementation of the security policies has been find out:

- dealing with scare budgets,

- $\quad$ senior manager do not place enough importance to securities issues,

- inappropriate software/hardware solution,

- $\quad$ human factor (staff shortage).

Overcoming problems: Major factor, that is keeping the customers away from making more transactions over the internet, is: web sites not being able to satisfy customer needs - poor design (35\% of companies). Also fear of being robbed by the hackers and losing their money stands for up to $32 \%$ of companies.

Barriers in implementing the e-commerce: During investigation the prominent barriers were:

- resistance to new technology,

- difficulty of implementation,

- security as an over hyped problem,

- lack of skills, and

- lack of potential customer connected.

Internet impact on global market: Regarding the implication of e-commerce on the global marketplace: For the year 2010 there is an opinion that the internet influences the global marketplace, for the year 2014 the majority believes that the internet is having a major impact on the global marketplace. Analysis of the results shows that in 2010 it was (within the confidential limits with a $5 \%$ significance level) between $54 \%$ and $74 \%$ and in 2014 between $82 \%$ and 95 $\%$ of such companies.

How the government can help in implementing e-commerce: Government can help in the implementation of ecommerce by: promoting cross boundaries cooperation, removing unnecessary barriers, ensuring the neutrality among electronic / conventional businesses, establishing a self, reliable environment for consumers, and by effective taxation. 


\section{Discussion}

E-commerce offers a large number of advantages to the companies. Data can be exploited far more readily on the internet then the real world and eliminate the scope of brokers. Price comparisons become far easier. This suggests that the internet can be a strong price-deflation mechanism: rising of the prices is harder when the customers instantly compare them with others. Internet affects both the aggregate supply and demand and is a greater threat to major brands and prices. Internet technology erodes the "risk premium" that sellers have been able to extract from wary buyers. Buyer-led pricing and reverse auctions allow consumers to see the "price-floor" more easily than they can with traditional methods, internet encouraging highly rational shopping. A single website can be used to cover the globe.

Selling over the web: To understand the financial impact of web commerce, companies must capture the additional back end costs, which are incurring because of poor processes. Hence, companies must have a cost monitoring system in place for the web activities.

Differentiation on the web will come from our front-end processes: A front-end web site is often the easiest and least differentiating section of an effective web strategy. Any competitor can duplicate the product information and electronic orders from the web site. E-commerce leaders are now looking to differentiate themselves through relationships with suppliers and optimizing the physical flow of goods by creating improved margins and better customer service. They are also creating real-time visibility to inventory, capacity and transportation availability and are translating this into accurate order status and delivery date information for customers. A step further means creating dynamic pricing, promotions and product mix optimization based on real-time supply and demand data.

Logistics operations can handle e-commerce fulfilment: Companies can choose either to outsource web commerce fulfilment to third-party logistics providers or to restructure their internal warehouse operations and systems. Companies with multiple warehouses must decide whether to reconfigure all their warehouses to support this activity or whether they should designate one warehouse as the web commerce fulfilment center. An efficient process will also need to be set up for handling returned goods.

Existing supplier relations will support e-commerce: E-commerce will require a dramatic change in mind-set toward suppliers. Retailers must create a partnership with manufacturers to enable efficient fulfilment and to discourage manufacturers from direct selling. Companies must rethink their relationships with suppliers and sourcing, fulfilment strategies using network and capacity planning tools to determine the costs of different fulfilment scenarios and build a cost-optimized physical network to support web commerce.

Company's order management system can handle e-commerce: Many order management systems are designed to support a small number of pre-defined customers. Selling over the web requires these systems to be revamped to support transactions from vast numbers of previously unknown customers. Therefore, companies must plan to extend the capabilities of their order management system, especially in the area of web self-service.

We can now sell effectively to anyone around the globe: Most companies are excited for increasing their global presence. However, company's back-end systems are often ill equipped to handle international trade deals. Companies that overlook the complexities inherent in shipping internationally will alienate customers by giving them unreliable information about lead times and total shipment costs. These companies are exposing themselves to increased risk of violating export compliance laws, resulting in fines and negative publicity.

\section{Conclusion}

Nowadays, the purchasing climate and the products are changing quickly. Economic and marketing forces and digital convergence have influenced how industries are repositioning themselves to take advantage of new opportunities, including the creation of entirely new service delivery channels, the developments of new markets for existing products and the development of new information-based products for online environment [18]. However, before companies can exploit the capabilities of e-commerce and make it an industrial-strength toll for business, they need to understand the technological framework better (Fig. 6).

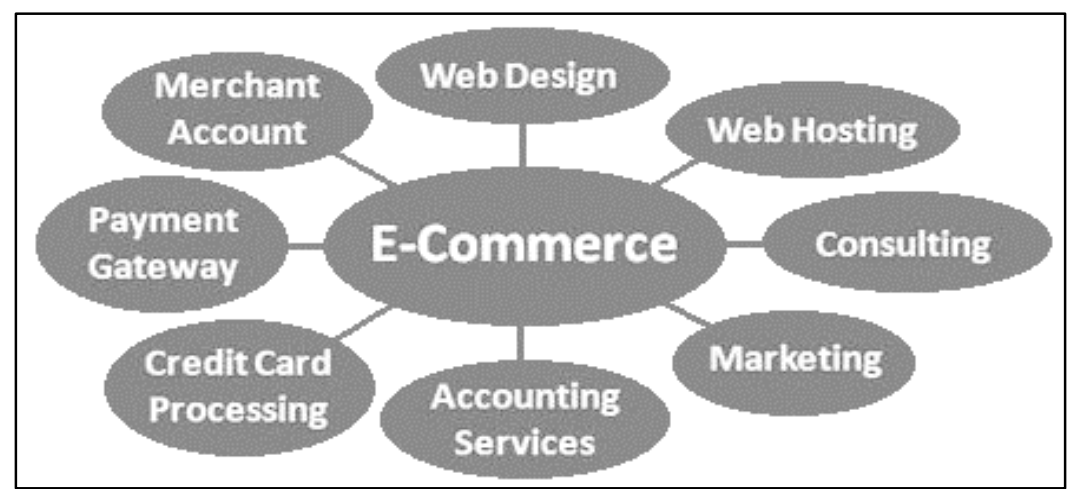

Fig. 6. E-commerce solutions 
Several factors will help define the future of e-commerce. The technology will continue to propagate through all commercial activity. The revenues are expected to rise at an annualized rate of about $14 \%$ per year. The number of products and services sold online and the size of the average purchase order will continue to grow at near double-digits rates. The results demonstrate that e-commerce is shaping the way in which business of the future will be transacted. Given the general recognition of the role of e-commerce in overcoming national, geographical and temporal boundaries to trade, companies those who wants to be at the front of global competition in their particular markets cannot ignore ecommerce any longer. E-commerce impacts supply chain management in different ways like:

- cost efficiencies (reduced costs, better data accuracy, accelerated business cycle, and enhanced customer service),

- changes in the distribution system (more flexibility in managing the increasingly complex movement of products and information, closed link between customers and distribution centers),

- customer orientation (support of logistics and transportation services for both internal and external customers),

- $\quad$ shipment tracking (users can establish an account and obtain real time information about shipments).

In the future the supply chain will be widely electronically integrated (i.e. e-supply chain). Market changes and sales orders are available online throughout the entire supply chain. The electronic link between customers and suppliers covers everything from order management, intelligent forecast systems, and scheduling functions, to virtual marketplaces [1]. Merging these fields is a key area of concern for contemporary managers and researchers.

This paper demonstrates the impact of e-commerce on business models in the selected industries. The exponential growth of e-business, together with the emergence of a low-cost, worldwide communication network is reshaping the way that the individuals and companies carry out their transactions.

Future work will include additional research, segmented for different sorts of activities in order to get a more accurate overview of the implications of e-commerce on various industries in the world.

\section{References}

[1] Kosiur, D., Understanding Electronic Commerce (How online transactions can grow your business), Microsoft Press, Redmond, 1997.

[2] M. O'Grady, Forrester research online retail forecast, 2013 to 2018 (Western Europe), from https://www.forrester.com/Forrester+

Research+Online+Retail+Forecast+2013+To+2018+Western+Europe+Q4+2014+Update/fulltext/-/E-res120541, accessed on 10-05-2015.

[3] P. Chatterjee, D.L. Hoffman, T.P. Novak, Modeling the Clickstream: Implications for Web-Based Advertising, Marketing Science, 22 (2003) 4, 520-541.

[4] B. Witcher, Z.D. Wigder, S. Mulpuru, P. Sheldon, R. Katz, Avoid the rush and deal with the realities of same-day delivery,

from https://www.forrester.com/Avoid+The+Rush+And+Deal+With+The+Realities+Of+SameDay+Delivery/fulltext//E-res116390, accessed on 12-05-2015.

[5] C.K. Laudon, C.G. Traver, E-commerce: business, technology, society, 10th ed., Pearson, New York, 2014.

[6] KPMG Consulting, Perspectives, Publication series Global, London, 2014.

[7] A. Lella, ComScore: Insights, from https://www.comscore.com/Insights/Press-Releases/2014/1/2013-HolidaySeason-US-Desktop-ECommerce-Spending-Reaches-Record-465-Billion-Up-10-Percent-vs-Year-Ago/, accessed on 02-06-2015.

[8] Z. Qin, S. Li, Y. Chang, F. Li, E-Commerce Strategy, Springer, Berlin, 2014.

[9] R. Kalakota, A.B. Whinston, Electronic Commerce - A Manager's Guide, Addison Wesley, Reading, 1997.

[10] W. R. Killingsworth, Design, analysis, and optimization of supply chains, Business Expert Press, New York, 2011.

[11] M. Christopher, Logistics \& Supply Chain Management, 4th ed., Pearson, Harlow, 2011.

[12] D.J. Fang, C. Li, Simulation-based hybrid approach to robust multi-echelon inventory policies for complex distribution networks, International Journal of Simulation Modelling, 13 (2014) 3, 377-387

[13] M. Diez, J. Mula, F. Campuzano-Bolarin, Improvement of a distribution network of a direct sale cosmetics supply chain, International Journal of Simulation Modelling, 13 (2014) 1, 16-29

[14] B.M. Beamon, Measuring supply chain performance, International Journal of Operations \& Production Management, 19 (1999) 3, 275-292.

[15] T. Banyai, P. Veres, B. Illes, Heuristic supply chain optimization of networked maintenance companies, Procedia Engineering, 100 (2015) 46-55.

[16] M. Leber, C. Weber, F. Adam, M. Leber, Mobile application as an innovative supply chain concept and the impact of social capital, International Journal of Simulation Modelling, 13 (2014) 2, 135-146 
[17] Y. Luo, M.-C. Zhou, R.J. Caudill, An integrated e-supply chain model for agile and environmentally conscious manufacturing, IEEE/ASME Transactions on Mechatronics, 6 (2001) 4, 377-386.

[18] European Commission, Communication on e-commerce and other online services (2012), from http://ec.europa.eu/internal_market/e-commerce/communications/2012/index_en.htm, accessed on 15-12-2014.

[19] The European Consumer Centres Network, European Consumer Centres E-commerce report 2014, from http://www.ecc.fi/globalassets/ ecc/ajankohtaista/raportit/ecc-e-commerce-report-2014---traders.pdf, accessed on 02-02-2015.

[20] Ecommerce Europe, Facts \& Figures, from http://www.ecommerce-europe.eu/facts-figures, accessed on 30-032015.

[21] Chamber of Commerce and Industry of Slovenia, Economic and trade information on Slovenia, from http://eng.gzs.si/vsebina/Market-Intelligence/Economic-and-Trade-Information-on-Slovenia, accessed on 17-042015. 